\title{
OS EFEITOS ECONÔMICOS DO ROMPIMENTO DE BARRAGEM DE RESIIDUOS: DIVULGAÇÕES NAS DEMONSTRAÇÕES CONTÁBEIS COMPARATIVAMENTE À GRANDE MÍDIA
}

\author{
THE ECONOMIC EFFECTS OF THE WASTE DAM BREAK: \\ DISCLOSURES IN THE FINANCIAL STATEMENTS \\ COMPARED TO MAINSTREAM MEDIA
}

Data de submissão: $21 / 12 / 2016$ Aceite: $22 / 10 / 2017$

Maísa de Souza Ribeiro ${ }^{1}$ Márcio da Silva Toledo Junior ${ }^{2}$

\section{RESUMO}

O Brasil acompanhou, por meio da imprensa, os fatos envolvendo a empresa Samarco S.A., a mineradora controlada pela Vale S.A. e pela BHP Billinton Brasil Ltda., a qual falhou na conservação dos seus depósitos de resíduos, tornando-se responsável por impactos relevantes de ordem ambiental, social e econômica. Inseridas nesse contexto, as informações contábil-financeiras relacionadas ao meio ambiente ganham relevância por representarem o sacrifício expressivo de benefícios econômicos e por relacionarem-se com os stakeholders interessados na prestação de contas, na situação patrimonial e nos efeitos na performance. Diante disso, conhecidos os principais efeitos do acidente em Mariana, Minas Gerais, o objetivo deste estudo foi verificar as evidenciações de provisões e dos passivos contingentes relacionados ao ocorrido nas demonstrações contábeis das empresas envolvidas. Constatou-se que os valores definidos no Termo de Transação e de Ajustamento de Conduta foram contabilizados e/ou inseridos nas notas explicativas, exercendo efeito expressivo no resultado e na situação do patrimonial. As controladoras restringiramse a apresentar breve comentário sobre o ocorrido, sem, contudo, mencionar qualquer responsabilidade sobre o caso; e uma delas notificou a ação movida por investidores estrangeiros por falta de informações sobre o caso e os riscos envolvidos.

Palavras-chave: provisão ambiental, passivos contingentes ambientais, caso Samarco, responsabilidade socioambiental.

\footnotetext{
1 Possui graduação em Ciências Contábeis pela Pontifícia Universidade Católica de São Paulo, mestrado em Controladoria e Contabilidade pela Universidade de São Paulo e doutorado em Controladoria e Contabilidade pela Universidade de São Paulo. Atualmente é professora titular do Departamento de Contabilidade da FEA-RP/USP. São Paulo. São Paulo. Brasil. E-mail: maisorib@usp.br

2 Possui graduação em andamento em Economia Empresarial e Controladoria pela Faculdade de Economia, Administração e Contabilidade - USP, FEAC/USP. São Paulo. São Paulo. Brasil. E-mail: marcio.toledo@usp.br
} 


\begin{abstract}
Brazil followed, through the press, the facts involving the company Samarco S.A., the mining company controlled by Vale SA and BHP Billiton Brazil Ltda., which failed in the conservation of their waste deposits and became responsible for significant impacts environmental, social and economic order. Inside this context, the accounting and financial information related to the environment become relevant due to represent the expressive sacrifice of economic benefits and by relate themselves with stakeholders interested in accountability, equity situation and effects on performance. Thus, known the main effects of the accident in Mariana, Minas Gerais, the goal of the study was to verify the disclosures of provisions and contingent liabilities related to what happened in the involved companies' financial statements. It was found that the values defined in the Terms of Transaction and Adjustment of Conduct were recorded and/or inserted in explanatory notes, exerting significant effect on the result and equity situation. The Parent Companies restricted to present a brief comment about the incident, without however to mention any responsibility about the case; but one of them has notified the lawsuit filed by foreign investors due to the lack of information about the case and the risks involved.
\end{abstract}

Keywords: environmental provisions, contingent environmental liabilities, Samarco case, socio-environmental responsibility.

\title{
1 INTRODUÇÃO
}

O desenvolvimento das atividades econômicas e empresariais, aliado aos extensos avanços tecnológicos experimentados pela humanidade, afeta significativamente o meio ambiente, seja pela emissão de diversos tipos de poluentes, pelo desmatamento ou pelo crescente consumo dos recursos naturais renováveis e não renováveis. Todos esses aspectos e as inúmeras modificações observadas no meio ambiente representam um desafio à capacidade de autorrenovação da natureza e vêm lançando diversas dúvidas sobre as condições de vida da geração não só presente, mas principalmente futura.

No presente cenário, os descontroles das atividades operacionais provocam impactos ainda mais relevantes de diversas ordens, os quais chocam a sociedade, colocando-a em estado de alerta quanto às limitações a que o planeta está sujeito. Diante disso, estudos anteriores registraram eventos significativos nos quais a fauna, a flora, a comunidade e as atividades econômicas foram drasticamente afetadas por falhas operacionais de algumas atividades empresariais, tais como os casos do Exxon Valdez, no Alaska, em 1987, da Baia da Guanabara, no Rio de Janeiro, em 2001 e da Deepwater Horizon, no Golfo do México, Estados Unidos, em 2010 (PATTEN, 1992; BERTOLI; RIBEIRO, 2006; COETZEE; STADEN, 2011). Nesses contextos, a contabilidade assume função de suma importância, pois, além apresentar dados referentes à performance operacional, pode indicar o desempenho organizacional ante as questões ambientais (BERTOLI; RIBEIRO, p. 118).

Conforme Patten (1992, p. 471) e Tinker e Niemark (1987, p. 84), o início do interesse social pelo tema data das décadas de 1960 e 1970, período em que surgiu, de forma mais enfática, a percepção da sociedade quanto às consequências advindas do crescimento corporativo. As informações contábeis relacionadas ao meio ambiente - passivos ambientais - das empresas envolvidas em acidentes de grandes proporções podem representar sacrifício de benefícios econômicos de ordem relevantes para a recuperação ambiental e demais impactos na sociedade. Entretanto, a definição de valores pode envolver significativa diversidade de elementos, os quais podem se diferenciar de elaborador para elaborador, dependendo dos interesses envolvidos.

Em 2015, o Brasil assistiu ao impacto de uma empresa de mineração, a Samarco, a qual falhou na conservação dos seus depósitos de resíduos, ocasionando o rompimento da barragem 
de Fundão, em Mariana, Minas Gerais. Dentre as principais implicações do acidente, constam o total de 18 vítimas fatais, 329 famílias atingidas e 1.265 desabrigados, alojados provisoriamente em hotéis e pousadas da região, até o início de março de 2016; um impacto direto de 1.469 hectares ao longo dos 77 quilômetros de curso d'água; perdas do patrimônio cultural; e comprometimento de diversas atividades econômicas, tais como pesca, agricultura, pecuária e turismo (BRAGON, 2015; EMBRAPA, 2015; IBAMA, 2015; ROMPIMENTO, 2015; SANTIAGO, 2015; CORPO, 2016).

Tal situação requer identificação, mensuração, reconhecimento e divulgação dos aspectos econômicos dos eventos ocorridos nos relatórios contábeis produzidos pelas empresas responsáveis - a empresa em si e suas controladoras -, tendo em vista o impacto sobre suas situações patrimoniais. Assim, esta pesquisa objetiva responder às seguintes perguntas: há correspondência entre as informações divulgadas pela mídia e pelos órgãos ambientais e aquelas inseridas nas demonstrações contábeis das companhias envolvidas no caso Samarco? Qual é o efeito dos impactos em questão no patrimônio e resultado das companhias envolvidas?

Dessa forma, o objetivo desta pesquisa consiste em comparar as divulgações feitas pelas companhias responsáveis pelo acidente ambiental ocorrido no município de Mariana, Minas Gerais, em novembro de 2015, àquelas divulgadas pela mídia, identificando, ainda, os efeitos patrimoniais e no resultado do período desse acidente. Espera-se que a pesquisa contribua com a identificação da relevância do evento para a continuidade da companhia, bem como da completude no processo de comunicação entre a sociedade e os interessados na sua continuidade.

\section{REFERENCIAL TEÓRICO}

\subsection{Aspectos contábeis: provisões e passivos contingentes}

No ano de 2010, as normas contábeis nacionais, correlacionadas com as internacionais, vieram reforçar os princípios contábeis quanto ao reconhecimento dos eventos e das transações no que concerne a uma maior clareza acerca da ocorrência do fato gerador, inclusive, daquele relacionado às obrigações. Especificamente, o Pronunciamento Técnico CPC 25 (IAS 37 do IFRS International Financial Reporting Standards) veio tratar de provisões e passivos contingentes, fortalecendo o tratamento quanto ao reconhecimento, à mensuração e à divulgação de obrigações.

\subsubsection{Provisões}

Segundo Hendriksen e Van Breda (2007), as provisões representam um sacrifício futuro de benefícios econômicos de provável ocorrência, o qual é oriundo de obrigações presentes da entidade e possui a sua liquidação atrelada a um ou mais eventos futuros. Tal inferência corrobora a definição apresentada no escopo do CPC 25: as provisões são obrigações presentes que culminarão com uma provável saída de recursos que incorporam benefícios econômicos para liquidar a obrigação (COMITÊ DE PRONUNCIAMENTOS CONTÁBEIS, 2009; HENDRIKSEN; VAN BREDA, 2007).

Conforme ludícibus (2004), o problema principal do passivo reside em quando reconhecê-lo e registrá-lo, e não na sua mensuração. Nesse contexto, o CPC 25 reforça a necessidade de existência de um evento passado ou presente, que crie e conduza a uma obrigação presente, legal ou não formalizada (COMITÊ DE PRONUNCIAMENTOS CONTÁBEIS, 2009; IUDÍCIBUS, 2004).

O evento que cria a obrigação implica uma provável saída de recursos, ou seja, o consumo de benefícios econômicos, e a partir disso exigir-se-á que uma estimativa suficientemente confiável do valor possa ser realizada para o reconhecimento. Tais requisitos se mostram em 
consonância como Hendriksen e Van Breda (2007), que, ao considerarem o SFAS 5 - Statement of Financial Accounting Standards № 5 - Accounting for Contingencies -, inferem que o reconhecimento das obrigações deve satisfazer a definição de passivo, havendo elevada probabilidade de ocorrência do evento futuro e confiabilidade na definição do valor (COMITÊ DE PRONUNCIAMENTOS CONTÁBEIS, 2009; HENDRIKSEN; VAN BREDA, 2007).

Quanto à estimativa, ela deve ser oriunda do julgamento da administração da empresa, o qual poderá ser complementado pelas experiências semelhantes passadas e até mesmo, em alguns casos, pelos relatórios de peritos independentes. $O$ valor deverá ser a melhor estimativa do desembolso exigido para a liquidação da obrigação presente na data do balanço; e os riscos, as incertezas e os eventos futuros deverão ser refletidos no montante estimado. Além disso, as evidências consideradas deverão incluir eventos subsequentes à data do balanço identificados antes da data de autorização deste (COMITÊ DE PRONUNCIAMENTOS CONTÁBEIS, 2009).

$O$ pleno atendimento aos requisitos de reconhecimento mencionados anteriormente implica a classificação da obrigação como provisão a ser reconhecida no passivo das demonstrações financeiras da empresa, conforme determina o pronunciamento em questão.

\subsubsection{Passivos contingentes}

Já os passivos contingentes consistem em uma obrigação possível, resultante de eventos passados, que necessita da ocorrência, ou não, de um ou mais eventos futuros para caracterizar a responsabilidade da companhia (COMITÊ DE PRONUNCIAMENTOS CONTÁBEIS, 2009). Tanto o CPC 25 quanto Hendriksen e Van Breda (2007) afirmam que tais eventos não são contabilizados no balanço, mas somente divulgados em nota explicativa, devido às incertezas que envolvem o valor ou grau da exigibilidade. Em consonância, ludícibus (2004) sugere em tais casos a efetuação de uma descrição completa da contingência. Nas situações em que sejam remotas as probabilidades de imputação de obrigação à companhia, dispensa-se a informação em nota explicativa nas demonstrações contábeis. A reavaliação frequente do contexto que envolve as situações em questão é necessária para identificação de eventuais mudanças no cenário e, portanto, de mudança de grau de expectativa (COMITÊ DE PRONUNCIAMENTOS CONTÁBEIS, 2009; HENDRIKSEN; VAN BREDA, 2007; IUDÍCIBUS, 2004).

Nos casos em que se caracterizam parcelas de responsabilidades distribuídas entre duas ou mais entidades de dado desembolso, se forem atendidos os critérios de reconhecimento, o CPC 25 determina o provisionamento proporcional pelas partes envolvidas (COMITÊ DE PRONUNCIAMENTOS CONTÁBEIS, 2009).

\subsection{Teoria dos stakeholders e divulgações contábeis}

A teoria dos stakeholders apresentada por Freeman (1984) define os stakeholders como o grupo de indivíduos que influencia e/ou é influenciado pelo alcance de dada organização na busca de seus objetivos, tais como consumidores, governo, fornecedores, investidores, empregados e proprietários. A mútua influência inerente à relação empresa/stakeholders requerer da organização um cuidado quanto à sua atuação, pois é a partir da aprovação dos grupos de importância que a empresa obterá legitimidade para a sua performance (BUCCINA; CHENE; GRAMLICH, 2013). Desse modo, a entidade buscará acomodar as demandas dos grupos específicos que exerçam tal influência (FREEMAN, 1984), tarefa que, na maioria das vezes, não será simples, pois, como infere Freeman (1984), as demandas existentes podem apresentar-se de modo conflitante, o que exigirá da gestão poder de convencimento para manter a relação (BUCCINA; CHENE; GRAMLICH, 2013). 
Em meio a isso, as evidenciações contábil-financeiras podem ser impactadas pelo intuito de atender aos stakeholders de determinada organização (COETZEE; STANDEN, 2011), uma vez que constituem um meio de prestação de contas e de fornecimento do suprimento de informações referentes ao desempenho da entidade para os usuários externos (COMITÊ DE PRONUNCIAMENTOS CONTÁBEIS, 2011). Tal situação constitui um indício da necessidade de considerar a teoria dos stakeholders em análises de divulgações contábeis.

\section{METODOLOGIA}

A metodologia utilizada na presente pesquisa caracteriza-se como um estudo de caso de um acidente ambiental. Visando a uma maior confiabilidade, como sugere Martins (2006), o estudo é complementado por uma análise documental baseada nas demonstrações financeiras do ano de 2015 divulgadas pelas empresas envolvidas, nas informações publicadas em notas por elas em seus respectivos sites e em dados apresentados pelos órgãos competentes e pelos veículos de imprensa.

Yin (2001) define a estratégia de pesquisa denominada estudo de caso como "uma investigação empírica que investiga um fenômeno contemporâneo dentro de seu contexto da vida real, especialmente quando os limites entre o fenômeno e o contexto não estão claramente definidos" (p. 32). Entretanto, tal estratégia necessita da complementação de um conjunto de técnicas, pois

enfrenta uma situação tecnicamente única em que haverá muito mais variáveis de interesse do que pontos de dados, e, como resultado, baseia-se em várias fontes de evidências, com os dados precisando convergir em um formato de triângulo, e, como outro resultado, beneficia-se do desenvolvimento prévio de proposições teóricas para conduzir a coleta e a análise de dados (YIN, 2001, p. 32-33).

\section{O CASO}

No dia cinco de novembro de 2015, o município de Mariana e região tornaram-se foco dos noticiários devido ao rompimento da barragem de Fundão, a qual se localizava no distrito de Bento Rodrigues e era utilizada para armazenar rejeitos oriundos da mineração de ferro. A responsável pela barragem era a Samarco Mineração S.A., empresa brasileira fundada em 1977, de capital fechado e controlada em partes iguais pelas acionistas BHP Billiton Brasil Ltda. e Vale S.A., todas do setor de mineração (SAMARCO, 2016).

Segundo o Instituto Brasileiro do Meio Ambiente e Recursos Naturais (2015), a barragem continha 50 milhões de $\mathrm{m}^{3}$ de rejeitos de mineração de ferro, os quais, sob a forma de uma onda de lama, percorreram, aproximadamente, 663,2 quilômetros, atingindo 50 municípios e dois estados até chegar ao mar, após 17 dias do ocorrido, no distrito de Regência, em Linhares, Espírito Santo (BORGES, 2015). Ao percorrer o trajeto, a onda foi destruindo ou danificando casas, igrejas, escolas, currais, pontes, plantações, criações, flora e fauna nativa, além da atividade turística (BORGES, 2015; IBAMA, 2015). A Empresa de Assistência Técnica e Extensão Rural do Estado de Minas Gerais (Emater-MG) também estimou que 195 propriedades foram atingidas, das quais $15,8 \%$ foram totalmente destruídas; as demais, $84,2 \%$, tiveram danos superior a $50 \%$ da estrutura geral (PRODUTORES, 2016).

Tais fatos geraram uma série de medidas punitivas contra a companhia Samarco S.A., como multas, bloqueios de recursos e acordos para reparação dos danos, todos com valores relevantes e estipulados independentemente em cada uma das ações (CRISTINI, 2015; JUSTIÇA, 2015; SAMARCO, 2015c). 
O Ibama aplicou a multa máxima - $\mathrm{R} \$ 50$ milhões - prevista na Lei de Crimes Ambientais n.o 9605/98, em seu artigo 75, para cada uma das cinco infrações identificadas: provocar riscos à saúde humana devido à poluição hídrica; tornar áreas impróprias para a ocupação; ocasionar a interrupção do abastecimento público de água; descumprir as exigências legais ao lançar resíduos; e provocar a mortandade de animais e perda da biodiversidade do percurso do Rio Doce, totalizando R\$ 250 milhões (BRASIL, 1998; IBAMA, 2015).

Já o governo estadual de Minas Gerais notificou a companhia, por meio da Subsecretaria Estadual de Fiscalização de Meio Ambiente, com uma multa no valor de $\mathrm{R} \$ 112.690 .376,32$, devido aos danos ambientais ocorridos em decorrência do rompimento da barragem de Fundão (SAMARCO, 2015a).

\subsection{Impactos}

Os danos causados pela onda de lama de rejeitos, segundo o laudo técnico preliminar do Ibama (2015), foram considerados como degressivos, isto é, quanto mais próximos ao ponto inicial do desastre, maiores foram os impactos e suas consequências. Baseando-se em tal dado, o distrito de Bento Rodrigues, Minas Gerais, pode ser apontado como o local mais prejudicado pela onda de lama.

\subsubsection{Impactos à sociedade}

Além das perdas de vida e de bens materiais já mencionadas, os danos englobaram o impacto ao modo de vida e aos valores éticos e culturais de populações ribeirinhas (povos que vivem nas beiras de rios), populações estuarinas (aqueles situados em áreas de transição entre o rio e o mar), indígenas e populações tradicionais. Diante disso, o laudo do Ibama também frisou as perdas relacionadas às identidades e referências tradicionais, culturais, religiosas e locais das populações afetadas, que são de difícil mensuração e, consequentemente, reparo (IBAMA, 2015).

\subsection{Impactos ambientais}

Os impactos ambientais do desastre encontram-se subdivididos em danos à flora, à fauna e aos recursos hídricos das áreas atingidas.

\subsubsection{Flora}

O acidente atingiu áreas de preservação permanente da vegetação remanescente do bioma brasileiro classificado como Mata Atlântica. Houve devastação de matas ciliares remanescentes, soterramento imediato de indivíduos de menor porte do sub-bosque e supressão de indivíduos arbóreos devido à ação de aporte de sedimentos provocada pela onda de lama. Tal fato provocou o comprometimento da resiliência - capacidade natural que um ecossistema perturbado possui de retornar as suas características originais, independente da ação humana - e dos processos de sucessão - sequência de comunidades de um dado ecossistema - da vegetação (IBAMA, 2015).

Adicionalmente, um estudo de autoria da Empresa Brasileira de Pesquisa Agropecuária (Embrapa) informou existir deficiência de fertilidade do solo devido à ação dos rejeitos contidos na onda de lama (EMBRAPA, 2015). 


\subsubsection{Fauna}

Os dados referentes aos impactos na fauna, segundo o Ibama (2015), concentraram-se na ictiofauna, herpetofauna, avifauna e mastofauna. Foram prejudicadas 80 espécies da ictiofauna (peixes da região), 28 espécies da herpetofauna (anfíbios e répteis), 112 da avifauna (aves) e 35 da mastofauna (mamíferos) (IBAMA, 2015).

\subsubsection{Recursos hídricos}

A onda de rejeitos oriunda do rompimento da barragem provocou um grande impacto na qualidade dos cursos d'água da região, requerendo da mineradora a contratação de quatro empresas de coleta de amostras em matrizes ambientais (IBAMA, 2015). Notou-se, a esse respeito, uma divergência entre a Samarco e o Ibama. Segundo a empresa, os rejeitos de mineração de ferro são compostos, basicamente, de água, partículas de óxidos de ferro e sílica ou quartzo, tendo sido classificados como não perigosos (SAMARCO, 2015b). Entretanto, o laudo do Ibama (2015) apontou alterações nos parâmetros referentes a metais totais.

Tal situação gerou danos diretos às atividades econômicas voltadas para a agricultura e pecuária de subsistência, presentes na extensão das cidades da região, impactando, ainda, atividades de drenagem, como informou o Ibama (2015) após a realização de sobrevoos na área afetada.

\subsection{Impactos ao patrimônio histórico e cultural}

O Ministério Público de Minas Gerais divulgou, em seu diagnóstico preliminar, que o patrimônio cultural atingindo era composto por inúmeras peças de arte sacra, igrejas históricas e dezenas de sítios históricos que registravam a atividade mineradora do século XVIII (BRAGON, 2015; SANTIAGO, 2015).

\subsection{Impactos econômicos}

O rompimento da barragem provocou danos às cadeias de produção econômica dos munícipios pelos quais a onda de rejeitos passou, incluindo as atividades agrícola, pecuária, pesqueira e turística, além dos serviços públicos.

\subsubsection{Atividade agrícola e pecuária}

A Emater-MG divulgou o resultado de levantamento do valor dos danos locais: um prejuízo de aproximadamente $\mathrm{R} \$ 23,2$ milhões dos produtores rurais atingidos pelo desastre, os quais se concentraram em áreas utilizadas para pastagem, capineiras, plantações de cana-de -açúcar, grãos e horticultura; R\$3,3 milhões referentes a financiamentos de crédito rural de 34 produtores; e 23,1 milhões relativos às propriedades afetadas (PRODUTORES, 2016).

O estudo da Embrapa (2015), a pedido do Governo Estadual de Minas Gerais, constatou a ausência de condições favoráveis ao desenvolvimento de atividades agropecuárias. Além disso, frisa-se o caráter de subsistência dessas atividades na região (EMBRAPA, 2015). 


\subsubsection{Atividade pesqueira}

Conforme apresentado pelo laudo preliminar do Ibama, o impacto econômico referente à atividade pesqueira será a redução de receitas econômicas por um período ainda não estimado, tendo em vista que o desastre provocou a mortandade de 11 toneladas de peixes (ROMPIMENTO, 2015). Estima-se que 1.249 pescadores artesanais profissionais foram afetados pelo desastre (IBAMA, 2015).

\subsubsection{Atividade turística}

Notícias de três semanas após o rompimento da barragem já constatavam os impactos ao turismo na região de Mariana, a qual era conhecida pelos atrativos culturais, históricos, religiosos e naturais, além de apresentar um turismo voltado aos negócios (MACIEL, 2015). O efeito econômico do referido impacto foi reduzido em função da obrigação da empresa de alojar todos os moradores que ficaram desabrigados. Assim, hotéis e residências locais não afetados foram contratados para essa finalidade (CAMARGOS; PARREIRAS, 2016).

\subsubsection{Serviço público}

O oferecimento de serviços públicos na área impactada ficou prejudicado em instituições de ensino, assistência e sistemas de emergências médicas, segurança pública, transportes locais, regionais e de longo curso, telecomunicações, geração e distribuição de energia elétrica, limpeza urbana, distribuição de combustíveis, serviço de controle de pragas, abastecimento de água e sistemas de coleta de esgoto (IBAMA, 2015).

\section{DIVULGAÇÃO CONTÁBIL DOS IMPACTOS SOCIOAM- BIENTAIS E ECONÔMICOS}

\subsection{Samarco}

A Samarco divulgou, em suas demonstrações financeiras do ano de 2015, informações referentes ao evento e suas implicações para o meio ambiente, para a sociedade e para própria empresa (SAMARCO, 2016). Tal fato coaduna com a teoria dos stakeholders, que prega a divulgação em função da necessidade de prestação de contas a todos aqueles interessados no desenvolvimento do negócio, principalmente aqueles que aportam capital, o que é aplicável nessa situação que exigiu da empresa a ampla divulgação de suas ações para informar a extensão dos danos, bem como as medidas tomadas para remediá-los.

A mineradora apresentou as influências do acidente e suas ações preliminares para sanar os impactos na nota explicativa de número três das demonstrações contábeis de 2015. Além disso, divulgou as futuras ações em consonância com o Termo de Transação e de Ajustamento de Conduta (TTAC), o qual foi estruturado em 41 programas (23 de natureza socioeconômica e 18 de natureza socioambiental) (SAMARCO, 2016).

Assim, estabeleceu-se que a Samarco será a responsável por prover os recursos a serem geridos por uma Fundação que seria administrada por nomes do setor privado e fiscalizada pelo governo, conforme ilustrado na Tabela 1, exposta a seguir. 
OS EFEITOS ECONÔMICOS DO ROMPIMENTO DE BARRAGEM DE RESÍDUOS:

DIVULGAÇÕES NAS DEMONSTRAÇÕES CONTÁBEIS COMPARATIVAMENTE À GRANDE MÍDIA

Tabela 1: Detalhamento do Termo de Transação e de Ajustamento de Conduta.

\begin{tabular}{|c|c|c|}
\hline \multicolumn{3}{|c|}{ Ações - Termo de Transação e de Ajustamento de Conduta } \\
\hline Ano Calendário & Valor (milhares) & Descrição \\
\hline $2016-2018$ & $\mathrm{R} \$ 4.400 .000$ & $\begin{array}{l}\text { Provimento do montante para as ações de reparação e com- } \\
\text { pensação (menos o montante já gasto ou alocado). }\end{array}$ \\
\hline $2019-2021$ & $\begin{array}{l}\text { Entre } R \$ 800.000 \text { e } R \$ \\
1.600 .000 \text { (valor de refe- } \\
\text { rência) }\end{array}$ & $\begin{array}{l}\text { Pagamento de contribuições anuais à Fundação, as quais de- } \\
\text { verão ser suficientes para cobrir a previsão de execução de } \\
\text { projetos de reparação e compensação para cada exercício. }\end{array}$ \\
\hline 2022 em diante & $\begin{array}{l}\text { O TTAC não especificou } \\
\text { valor máximo ou mínimo } \\
\text { a partir desta data. }\end{array}$ & $\begin{array}{l}\text { Os valores serão baseados no planejamento dos programas } \\
\text { aprovados. }\end{array}$ \\
\hline
\end{tabular}

Fonte: elaborada com base nos dados da Samarco (2016).

A partir dos montantes repassados, a Fundação deverá desembolsar $\mathrm{R} \$ 240.000$ por ano, por um período de 15 anos a partir de 2016, para a execução de projetos de compensação e $\mathrm{R} \$ 500.000$ em programas de coleta e tratamento de esgoto e de destinação de resíduos sólidos em determinadas áreas (SAMARCO, 2016).

Contrapondo-se ao divulgado, matérias do final de novembro de 2015 informavam que os valores a serem pagos pela mineradora estavam inicialmente previstos em $\mathrm{R} \$ 20$ bilhões, valor que tinha como base os laudos técnicos elaborados pelo Ibama e pela Agência Nacional de Águas (ANA) e que foi aceito tanto pela União e quanto pelos Estados envolvidos. O valor mencionado seria utilizado em medidas voltadas à redução de danos, à revitalização da Bacia do Rio Doce e ao pagamento de indenizações à população impactada. Além disso, havia a previsão de gastos em R\$ 4 bilhões para recuperação de áreas de preservação permanente e R\$ 3 bilhões para a revitalização das nascentes de rios contaminados (PERON, 2015).

Abordando tal assunto, o advogado-geral do Estado de Minas Gerais, Onofre Batista, alegou que a diferença observada entre os valores é decorrente de divergências entre os orçamentos que nortearam o poder público ao elaborar a ação de $\mathrm{R} \$ 20$ bilhões e os apresentados pela Samarco, a qual teria argumentado em favor do cumprimento das exigências do acordo, desembolsando valores inferiores aos anteriormente divulgados (PERON, 2016). Os valores registrados contabilmente como provisões, baseados no TTAC, estão demonstrado a seguir.

\subsubsection{Provisões reconhecidas nas demonstrações financeiras}

As informações referentes ao rompimento da barragem de Fundão, à luz do CPC 25, caracterizaram o acidente como um evento que cria obrigação presente para a mineradora Samarco, já que a situação não propiciou outra alternativa a não ser a reparação dos impactos nas mais diferentes frentes até aqui abordadas. O cenário em si e as ações e medidas em curso, além das diversas informações referentes a montantes a serem desembolsados para a recuperação dos danos, já indicavam como provável a saída de recursos que incorporam benefícios econômicos da entidade para a reparação de sua obrigação (COMITÊ DE PRONUNCIAMENTOS CONTÁBEIS, 2009).

Para o reconhecimento de provisões, fez-se necessária a formulação da melhor estimativa dos valores a serem desembolsados para a liquidação da obrigação presente na data do balanço. Espera-se que os valores acordados no TTAC constituam a melhor estimativa do montante das provisões para companhia, as quais constam presentes no item (g), Provisões diversas, 
da Nota Explicativa no 3. No entanto, tais valores são bastante distintos daqueles expostos pelos meios de comunicação, seja pela difícil mensuração ou pelos efeitos da ansiedade da mídia em especular o assunto antes da elaboração de informações técnicas mais precisas. Os valores acertados no TTAC foram distribuídos conforme indica a Tabela 2.

Tabela 2: Detalhamento das provisões constituídas pela Samarco.

\begin{tabular}{|c|c|c|}
\hline \multicolumn{3}{|r|}{ Provisões } \\
\hline Título & $\begin{array}{c}\text { Valor (milha- } \\
\text { res) }\end{array}$ & Descrição \\
\hline $\begin{array}{l}\text { Ações Emergen- } \\
\text { ciais e Migrató- } \\
\text { rias }\end{array}$ & $\mathrm{R} \$ 304.831$ & $\begin{array}{l}\text { Custos relacionados às acomodações provisórias das pessoas em } \\
\text { hotéis e pousadas; transferência das famílias para moradias aluga- } \\
\text { das; reparação ou reconstrução das instalações de abastecimento } \\
\text { de água; abastecimento com água potável e mineral às comunida- } \\
\text { des impactadas; aquisição de equipamentos de segurança e mate- } \\
\text { rial de apoio para o trabalho dos bombeiros, defesa civil etc.; con- } \\
\text { sultorias ambientais; monitoramento e avaliações da qualidade da } \\
\text { água do Rio Doce de caráter emergencial; e instalação de barreiras } \\
\text { para contenção de plumas no litoral do Espírito Santo. }\end{array}$ \\
\hline $\begin{array}{l}\text { Programas Repa- } \\
\text { ratórios }\end{array}$ & $\mathrm{R} \$ 5.920 .148$ & $\begin{array}{l}\text { Medidas e ações de cunho reparatório que têm por objetivo mi- } \\
\text { tigar, remediar e/ou reparar impactos socioambientais e socioe- } \\
\text { conômicos, tais como: levantamento e cadastro dos impactados; } \\
\text { proteção e melhoria da qualidade de vida dos povos indígenas; pre- } \\
\text { servação da memória histórica, cultural e artística; comunicação, } \\
\text { participação, diálogo e controle social; reconstrução e recuperação } \\
\text { das comunidades e infraestruturas impactadas; assistência aos ani- } \\
\text { mais; auxílio financeiro emergencial aos impactados; revegetação } \\
\text { e recuperação ambiental; conservação da biodiversidade aquática; } \\
\text { manejo dos rejeitos decorrentes considerando conformação e es- } \\
\text { tabilização in situ, escavação, dragagem, transporte, tratamento e } \\
\text { disposição; e melhoria dos sistemas de abastecimento de água. }\end{array}$ \\
\hline $\begin{array}{c}\text { Programas } \\
\text { Compensatórios }\end{array}$ & $R \$ 3.296 .438$ & $\begin{array}{l}\text { Ações que visam compensar impactos não mitigáveis ou reparáveis } \\
\text { advindos do rompimento da barragem, como, por exemplo: apoio } \\
\text { à pesquisa para desenvolvimento e utilização de tecnologias socio- } \\
\text { econômicas aplicadas à remediação dos impactos; recuperação e } \\
\text { diversificação da economia regional com incentivo à indústria; estí- } \\
\text { mulo à contratação local; recuperação de áreas de preservação per- } \\
\text { manente; recuperação de nascentes; fortalecimento das estruturas } \\
\text { de triagem e reintrodução da fauna silvestre; coleta e tratamento } \\
\text { de esgoto e destinação de resíduo sólido; e educação ambiental e } \\
\text { preparação para emergências ambientais. }\end{array}$ \\
\hline $\begin{array}{l}\text { Outras Ações não } \\
\text { Contempladas no } \\
\text { Acordo }\end{array}$ & $\mathrm{R} \$ 483.385$ & $\begin{array}{l}\text { Englobam outros desembolsos necessários para o cumprimento de } \\
\text { ações derivadas do rompimento da barragem de Fundão, mas que } \\
\text { não foram classificadas nos programas do TTAC. }\end{array}$ \\
\hline Total & $\mathrm{R} \$ 10.004 .802$ & $\begin{array}{c}\text { O total informado está subdividido em } \mathrm{R} \$ 1.949 .964,00 \text { no Passivo } \\
\text { Circulante e } 8.054 .838,00 \text { no Passivo não Circulante, sendo que } \\
\text { este deve envolver, pelo menos, } 15 \text { anos. }\end{array}$ \\
\hline
\end{tabular}

Fonte: elaborada com base nos dados da Samarco (2016).

Na explanação da referida nota explicativa, expôs-se que as provisões constituídas foram descontadas a valor presente, utilizando a taxa livre de risco de $7,185 \%$ ao ano, a qual toma como base títulos de dez anos do Brasil no mercado internacional com data de referência 31 de dezembro de 2015 obtidos na Bloomberg (GTUSDBR10Y), e considerado o fluxo de desembolso 
esperado nos próximos 15 anos até 31 de dezembro de 2030 (SAMARCO, 2016). Cabe ressaltar que o desconto a valor presente se faz necessário devido ao longo prazo envolvido até o cumprimento da obrigação e ao valor do dinheiro no tempo.

\subsubsection{Passivos contingentes em notas explicativas}

A título de passivos contingentes, a entidade apresenta, no item (h) da nota explicativa

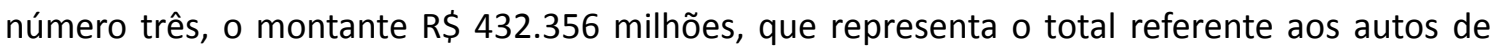
infração. A mineradora classificou o valor como uma expectativa de perda possível devido a não ter sido emitida uma resposta quanto à cobrança dos órgãos ambientais - Ibama, Secretaria de Estado de Meio Ambiente e Desenvolvimento Sustentável (SEMAD) e Secretaria de Controle e Fiscalização Ambiental Integrada (SUCFIS) (SAMARCO, 2016).

Quanto ao referido montante, mesmo representando a melhor estimativa para liquidação da obrigação, a companhia alega que por si só não permite o reconhecimento de provisões, pois ele se encontra comprometido com a ocorrência ou não de eventos futuros - posicionamento de órgãos ambientais -, os quais fornecerão elementos que caracterizam uma saída de recursos econômicos provável.

Sobre o mesmo tópico, evidenciou-se que o acidente implicou também diversos outros processos de natureza cível, ambiental e trabalhista para a entidade, com a finalidade de reparação, remediação e indenização dos impactos do acidente. Nesse caso, o não reconhecimento de provisões para tais ações se baseia no fato de o TTAC abranger ações ajuizadas contra a companhia que possuam os mesmos propósitos (SAMARCO, 2016). Dessa forma, falta tanto o evento futuro que caracterizará a saída de recursos como provável - decisões judiciais - quanto a mensuração confiável (COMITÊ DE PRONUNCIAMENTOS CONTÁBEIS, 2009).

\subsection{Divulgações das controladoras}

Em função de a Samarco S.A. ser uma joint venture das empresas Vale S.A. e BHP Billinton Brasil Ltda e em função de o CPC 25 abordar a possibilidade de parcelas de responsabilidades de duas ou mais entidades quanto a dado desembolso, torna-se necessário averiguar o conteúdo divulgado nas demonstrações financeiras de 2015 de ambas as empresas controladoras.

\subsubsection{Vale S.A.}

A Vale S.A., detentora de $50 \%$ da participação acionária da joint venture, informou no item de impactos contábeis no investimento, nota explicativa de número quatro de evento relevante, os desdobramentos do rompimento da barragem de Fundão. Nela, a controladora informa: o reconhecimento dos efeitos do ocorrido limitado à participação por meio do método de equivalência patrimonial; o não impacto ao seu fluxo de caixa no exercício encerrado em 31 de dezembro de 2015; o não recebimento de pedido de assistência financeira da controlada; a não obrigação de providenciar recursos para a controlada, de acordo com a legislação brasileira e com os termos do acordo de constituição da controlada; a redução para zero do investimento da Vale na Samarco; e o registro de nenhum passivo nas demonstrações da controladora (VALE, 2016). É preciso observar, no entanto, que as controladoras são, sim, responsáveis, pelas companhias que controlam, ainda que em conjunto, tendo de assumir com estas todos os passivos que the são inerentes, principalmente, sob o ponto de vista da responsabilidade socioambiental do negócio. 
No iten b - Remediação Socioambiental, a controladora informa que a Samarco reconheceu provisões e passivos contingentes para remediação socioambientais, baseando-se nas informações disponíveis, porém sem a apresentação de valores. Já no item c - Contingencias, é relatada a incerteza quanto às ações judiciais, nas quais são citadas as controladoras e a controlada, em especial as ações cíveis no tribunal federal de Nova York, movidas pelos detentores de títulos da Vale, os quais alegam declarações falsas e/ou omissões quanto aos riscos envolvendo a barragem que se rompeu. Por fim, no item d-Seguros, é informado o não reconhecimento de nenhuma indenização nas demonstrações contábeis da controlada provenientes de seguros de risco operacional, responsabilidade civil geral e riscos de engenharia devido ao estágio inicial das negociações e à dependência da definição de cobertura (VALE, 2016).

\subsubsection{BHP Billinton}

A BHP Billinton, detentora dos outros $50 \%$ da Samarco, não realizou menções quando ao ocorrido na barragem de Fundão em suas demonstrações financeiras de 2015. A controladora somente se referiu à controlada em notas explicativas, as quais apresentam os investimentos em curso da entidade, os detalhes de suas participações acionárias, os setores de atuação e a evidenciação do método de avaliação utilizado (BHP BILLINTON, 2016). As normas internacionais, representadas pelo IAS 37, item 29, no tópico Contingent liabilities, em que se baseia o CPC 25, também exigem que a controladora assuma e divulgue suas responsabilidades em função de danos provocadas pelas empresas em que mantem investimentos.

\section{IMPACTOS SOBRE RESULTADO E PATRIMÔNIO LÎQUI- DO DA SAMARCO}

A contrapartida do reconhecimento das obrigações por meio das provisões deve ser contabilizada como despesa no período em que o evento ocorreu. Assim sendo, a demonstração de resultados permite ao usuário da informação abstrair as influências na composição do resultado final divulgado pela entidade. Objetivando tal propósito, o resultado do exercício findo em 31 de dezembro de 2015, divulgado pela Samarco, foi um prejuízo de R\$ 5.836 .517 milhares. Observa-se a presença das informações referentes às provisões nos subitens dos tópicos Custos dos Produtos Vendidos e Outras Despesas Operacionais. Na nota explicativa 24 - Custos dos Produtos Vendidos, é evidenciada a provisão para reforço das instalações da barragem no valor de R\$171.613 milhares. Já na nota explicativa 26 - Outras Despesas Operacionais, consta o montante de $R \$$ 9.833.189 milhares a título de provisão para recuperação socioambiental e socioeconômica. Ambos os valores somados configuram $\mathrm{R} \$ 10.004 .802$ milhares, conforme pode ser observado na Tabela 3, exposta a seguir.

Tabela 3: Análise do impacto das provisões no resultado do exercício.

\begin{tabular}{|c|c|c|}
\hline Item & Montante (milhares) & Porcentagem \\
\hline Prejuízo do Exercício & $\mathrm{R} \$ 5.836 .517$ & $100 \%$ \\
\hline $\begin{array}{c}\text { Provisão - Nota Explicativa 24 - reforço } \\
\text { das instalações }\end{array}$ & $\mathrm{R} \$ 171.613$ & $3 \%$ \\
\hline $\begin{array}{c}\text { Provisão - Nota Explicativa 26 - recupe- } \\
\text { ração socioambiental }\end{array}$ & $\mathrm{R} \$ 9.833 .189$ & $168 \%$ \\
\hline Total - Provisões & $\mathrm{R} \$ 10.004 .802$ & $271 \%$ \\
\hline
\end{tabular}

Fonte: elaborada com base nos dados da Samarco (2016). 
Depreende-se, a partir de tais dados, que a totalidade da influência das provisões no prejuízo relatado na demonstração do resultado - $171 \%$ - é oriunda do valor provisionado a título de recuperação socioambiental e socioeconômica, o qual representa $168 \%$ do valor do pre-

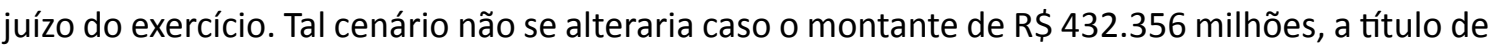
passivos contingentes, apresentasse expectativa de perda provável e fosse provisionado, como mostra a tabela 4 a seguir.

Tabela 4: Simulação do impacto das provisões e passivos contingentes no resultado do exercício.

\begin{tabular}{|c|c|c|}
\hline Item & Montante (milhares) & Porcentagem \\
\hline Prejuízo do Exercício & $\mathrm{R} \$ 5.836 .517$ & $100 \%$ \\
\hline Total - Provisões (1) & $\mathrm{R} \$ 10.004 .802$ & $171 \%$ \\
\hline Total de Passivos Contingentes & $\mathrm{R} \$ 432,356$ & $0,01 \%$ \\
\hline Total - Provisões e Passivos Contingentes & $\mathrm{R} \$ 10.005 .234 .356$ & $171 \%$ \\
\hline
\end{tabular}

Fonte: elaborada com base nos dados da Samarco (2016).

O prejuízo mencionado, por sua vez, também exerceu significativa influência no patrimônio líquido e no resultado do período. Observa-se que o volume de receitas foi afetado, possivelmente, em função de alterações operacionais decorrentes do acidente. $O$ impacto do acidente foi o responsável pelo expressivo prejuízo apurado no período, prejuízo esse que, ao ser incorporado ao patrimônio líquido, tornou-o negativo, o que significa que o montante do capital existente e as reservas de lucros acumulados até o exercício anterior não foram suficientes para cobrir o prejuízo do acidente.

\section{CONSIDERAÇÕES FINAIS}

A elaboração do presente estudo de caso permite inferir que o acidente do rompimento da barragem de Fundão em novembro de 2015 é icônico, tal como os casos do Exxon Valdez (1987), da Baia da Guanabara (2001) e do Deepwater Horizon (2010), pois suas origens, implicações e remediações despertaram não só o enfoque meramente informativo e judicial, mas também o enfoque acadêmico de inúmeras áreas. Em consonância, dentro da área contábil-financeira, a análise das demonstrações financeiras da Samarco S.A. permite concluir que o acidente e o posterior reconhecimento das provisões destruíram o resultado lucrativo esperado para o período da mineradora, bem como todo o patrimônio líquido da empresa, diretamente responsável pelo acidente.

Atendendo ao objetivo da pesquisa, verifica-se a importância da mídia e dos órgãos ambientais quanto à ilustração ampla dos impactos do acidente. Reconhece-se que ambos os atores abordam inúmeras frentes dos danos e fornecem vários pontos a serem explorados e debatidos pela sociedade, ainda que nem sempre coincidentes em função do momento em que são medidos e divulgados ou em função de interesses distintos.

Diferentemente do propósito das informações expostas na imprensa, as quais se caracterizam por uma geração e transmissão ágil de informações visando à máxima contemporaneidade com o fato abordado, as informações contábeis necessitam de um maior tempo para a sua evidenciação, pois suas confecções são fruto de rigorosas orientações norteadoras e de análises de informações disponíveis. Em consonância com tal ponto, observa-se que, embora a mídia tenha divulgado diversos valores e estimativas, o TTAC é que foi o documento oficial responsável pelo embasamento das mensurações e posterior reconhecimento das provisões. 
Contribuem para tal posicionamento as orientações técnicas emitidas pelos pronunciamentos contábeis, conforme apresentadas no Comitê de Pronunciamentos Contábeis (2009), as quais exigem, para o reconhecimento da provisão, o valor que representa a melhor estimativa do desembolso exigido para a liquidação da obrigação presente na data do balanço. Além disso, por tratar-se de um caso complexo, as mensurações especulativas ou preliminarmente elaboradas diferem das oficiais, já que podem não levar em conta o desconto a valor presente e o valor do dinheiro no tempo, entre outras especificidades técnicas.

No tocante aos passivos contingentes, o montante apresentado em nota explicativa pela mineradora, caracterizado como uma saída de recursos econômicos "possível" e, por conseguinte, não reconhecido como provisões somente foi justificado por meio do grau de incerteza associado à ocorrência ou não de eventos futuros. No entanto, a empresa poderia ter apresentado, adicionalmente, uma análise de pareceres semelhantes dos órgãos em questão como indicador mais fiel da probabilidade da saída de recursos.

Por fim, no que se refere aos relatos presentes nas divulgações contábil-financeiras da Samarco, entende-se que objetivaram esclarecer o que está sendo planejado e executado por parte da mineradora no sentido de amenizar o impacto gerado pelo rompimento da barragem. No contexto em questão, outros stakeholders, que não os acionistas, ganham destaque devido ao expressivo aumento da gama de interessados no reconhecimento das obrigações e condições para cumpri-las, ou seja, daqueles prejudicados pelo evento ocorrido, como os agentes econômicos e moradores locais, além dos órgãos governamentais responsáveis pela manutenção e preservação dos recursos naturais. Em relação às divulgações das controladoras, Vale S.A. e BHP Billinton, é relevante ressaltar que, ao restringir informações sobre responsabilidades do ocorrido, elas não satisfazem a teoria dos stakeholders, a qual se baseia na divulgação em função da necessidade de prestação de contas a todos aqueles interessados no desenvolvimento do negócio, direta ou indiretamente, fato que justifica a existência de ação movida por investidores estrangeiros por falta de informações sobre o caso e os riscos envolvidos, conforme divulgado pela Vale S.A.

\section{REFERÊNCIAS}

BERTOLI, Ana Lúcia; RIBEIRO, Maisa de Souza. Passivo Ambiental: Estudo de Caso da Petróleo Brasileiro S.A - Petrobrás. A Repercussão Ambiental nas Demonstrações Contábeis, em Consequência dos Acidentes Ocorridos. Revista de Administração Contemporânea, Vol.10, № 2, abr/jun 2006, P. 117-136. Disponível em: $<$ http://www.scielo.br/scielo.php?script=sci_ arttext\&pid=S1415-65552006000200007 >. Acesso em: 20 jan. 2016.

BHP BILLIYON. Resourcing global growth Annual Report 2015. BHP Billinton, 2016. Disponível em: <http://www.bhp.com/ / media/bhp/documents/investors/annualreports/2015/bhpbillitonannualreport2015. pdf?la=en>. Acesso em: 5 de mai. 2016.

BORGES, Juliana. Lama de barragem da Samarco chega ao mar no ES. G1 - Globo, Espírito Santo, 22 nov. 2015. Disponível em: <http://g1.globo. com/espirito-santo/noticia/2015/11/lama-debarragem-da-samarco-chega-ao-mar-no-es. html>. Acesso em: 23 nov. 2015.

BRAGON, Rayder. MP vai acionar Samarco por danos ao patrimônio cultural em Mariana. UOL Notícias: Cotidiano, Belo Horizonte, 20 nov. 2015. Disponível em: <http://noticias.uol.com. $\mathrm{br} /$ cotidiano/ultimas-noticias/2015/11/20/ mp-vai-acionar-samarco-por-danos-aopatrimonio-cultural-em-mariana.htm>. Acesso em: 12 dez. 2015.

BRASIL. Lei no 9605, de 12 de fevereiro de 1998. Disponível em: <http://www.planalto. 
gov.br/ccivil_03/leis/L9605.htm>. Acesso em: 15 fev. 2016.

CAMARGOS, Daniel; PARREIRAS, Mateus. De Mariana, em Minas, a Linhares, no Espírito Santo, tragédia prejudica o turismo. Estado de Minas, Minas Gerais, 3 jan. 2016. Disponível em: <http://www.em.com.br/app/noticia/ gerais/2016/01/03/interna_gerais,721565/ tragedia-prejudica-o-turismo.shtml>. Acesso em: 5 jan. 2016.

COETZEE, Charmaine M.; STADEN, Chris J. Disclosure responses to mining accidents: South African evidence. Accounting Forum, Vol. 35, Ed. 4, dez. 2011, P. 232-246. Disponível em: <http://www.sciencedirect.com/science/ article/pii/S0155998211000299>. Acesso em: 25 mar. 2016.

COMITÊ DE PRONUNCIAMENTOS CONTÁBEIS. Pronunciamento Técnico CPC 25: Provisões, Passivos Contingentes e Ativos Contingentes. Brasília, Junho, 2009. Disponível em: <http:// www.cpc.org.br/CPC/Documentos-Emitidos/ Pronunciamentos/Pronunciamento?ld=56>. Acesso em: 20.05.2016.

\section{Pronunciamento Conceitual Básico}

(R1): Estrutura Conceitual para Elaboração e Divulgação de Relatório ContábilFinanceiro. Brasília, Dezembro, 2011. Disponível em: <http://www.cpc.org.br/CPC/ Documentos-Emitidos/Pronunciamentos/ Pronunciamento? $\mathrm{ld}=80 \mathrm{>}$. Acesso em: 02.08.2016.

CORPO é achado dentro de caminhão em área do desastre de Mariana. G1 - Globo, Minas Gerais, 9 mar. 2016. Disponível em: <http://g1.globo.com/minas-gerais/desastreambiental-em-mariana/noticia/2016/03/ corpo-e-achado-dentro-de-caminhao-emarea-do-desastre-em-mariana.html>. Acesso em: 9 mar. 2016.

CRISTINI, Flávia. Um mês da tragédia - veja ações da polícia, MP, MPF, Justiça e Samarco. G1 - Globo, Minas Gerais, 05 dez. 2015.
Disponível em: <http://g1.globo.com/minasgerais/desastre-ambiental-em-mariana/ noticia/2015/12/um-mes-da-tragedia-vejaacoes-da-policia-mp-mpf-justica-e-samarco. html> Acesso em: 05 dez. 2015.

EMPRESA BRASILEIRA DE PESQUISA AGROPECUÁRIA (EMBRAPA). Tragédia em Mariana: produção em áreas atingidas está comprometida. 17 dez. 2015. Disponível em: $\quad<$ https://www.embrapa.br/busca-denoticias/-/noticia/8410974/tragedia-emmariana-producao-agropecuaria-em-areasatingidas-esta-comprometida>. Acesso em: 20 dez. 2015.

FREEMAN, R. E. Strategic Management: a Stakeholder Approach. Boston: Pitman. New York: Cambridge University Press. 1984.

HENDRIKSEN, Eldon S; VAN BREDA, Michael F. Teoria da Contabilidade. Tradução de Antonio Zoratto Sanvicente. 1a Edição-6a Reimpressão. São Paulo: Atlas, 2007.

INSTITURO BRASILEIRO DO MEIO AMBIENTE E DOS RECURSOS NATURAIS RENOVÁVEIS (IBAMA). Mineradora Samarco é multada em R\$ $\mathbf{2 5 0}$ milhões por catástrofe ambiental. 12 nov. 2015. Disponível em: <http://www. ibama.gov.br/publicadas/samarco-e-multadaem-r250-milhoes-por-catastrofe-ambiental>. Acesso em: 14 nov. 2015.

INSTITURO BRASILEIRO DO MEIO AMBIENTE E DOS RECURSOS NATURAIS RENOVÁVEIS (IBAMA); DIRETORIA DE PROTEÇÃO AMBIENTAL (DIPRO); COORDENAÇÃO GERAL DE EMERGÊNCIAS AMBIENTAIS (CGEMA). Laudo Técnico Preliminar: Impactos ambientais decorrentes do desastre envolvendo 0 rompimento da barragem de Fundão. 26 nov. 2015. Disponível em: <http://www.ibama. gov.br/phocadownload/barragemdefundao/ laudos/laudo_tecnico_preliminar_lbama. pdf>. Acesso em: 28 nov. 2015.

IUDÍCIBUS, Sérgio de. Teoria da Contabilidade. 7ạ Edição. São Paulo: Atlas, 2004. 
JUSTIÇA bloqueia $\mathrm{R} \$ 300$ milhões na conta da mineradora Samarco. G1 - Globo, Minas Gerais, 13 nov. 2015. Disponível em: <http:// g1.globo.com/minas-gerais/noticia/2015/11/ justica-determina-bloqueio-de-r-300-milhoesna-conta-da-samarco.html>. Acesso em: 16 nov. 2015.

MACIEL, Daniela. Turismo de Mariana e região padece "lama abaixo". Diário do Comércio, 28 nov. 2015. Disponível em: <http:// www.diariodocomercio.com.br/noticia. php?tit=turismo_de_mariana_e_regiao_ padece_lama_abaixo\&id=163276>. Acesso em: 10 dez. 2015.

MARTINS, Gilberto de Andrade. Estudo de caso: uma estratégia de pesquisa. 2aEdição. São Paulo: Atlas, 2006.

MPMG e MPF assinam Termo de Compromisso Preliminar com a Samarco, garantindo montante mínimo de $\mathrm{R} \$ 1$ bilhão para tutela ambiental emergencial. MPMG, Minas Gerais, 16 nov. 2015. Disponível em: <https://www.mpmg.mp.br/comunicacao/ noticias/mpmg-e-mpf-assinam-termo-decompromisso-preliminar-com-a-samarcogarantindo-montante-minimo-de-r-1-bilhaopara-tutela-ambiental-emergencial.htm\#. Vp5cDporl2w>. Acesso em: 10 dez. 2015.

PATTEN; Dennis M. Intra-industry environmental disclosures in response to the Alaskan oil spill: A note on legitimacy theory. Accounting Organitzations and Society, Illinois State University, USA, Vol. 17, no5, Jul. 1992, P. 471-475. Disponível em: <http:// www.sciencedirect.com/science/article/ pii/036136829290042Q>. Acesso em: 9 mar. 2016.

PERON, Isadora. União e Estados vão à Justiça e pedirão $\mathrm{R} \$ 20$ bi a mineradoras por desastre. 0 Estado de São Paulo, São Paulo, 28 nov. 2015. Caderno Metrópole, p. A20.
. Samarco fecha acordo e pagará $\mathrm{R} \$ \mathbf{b i}$ até 2018. O Estado de São Paulo, São Paulo, 27 fev. 2016. Caderno Metrópole, p. A21.

PRODUTORES rurais têm prejuízo de $\mathrm{R} \$ \mathbf{2 3 , 2}$ milhões com rompimento de barragem em Mariana. Empresa de Assistência Técnica e Extensão Rural de Minas Gerais (EmaterMG), 16 fev. 2016. Disponível em: <http:// emater.mg.gov.br/portal.cgi?flagweb=site_ tpl_paginas_internas $2 \& i d=17593 \#$. VuWnhvkrLIW>. Acesso em: 17 fev. 2016.

ROMPIMENTO de barragem da Samarco, em Mariana, completa um mês. G1 Globo, 5 dez. 2015. Disponível em: <http:// especiais.g1.globo.com/minas-gerais/2015/ desastre-ambiental-em-mariana/1-mes-emnumeros/>. Acesso em: 5 dez. 2015.

SAMARCO é notificada por governo de MG a pagar multa de R\$ 112 milhões. G1 - Globo, Minas Gerais, 19 nov. 2015a. Disponível em: <http://g1.globo.com/minas-gerais/desastreambiental-em-mariana/noticia/2015/11/ samarco-e-notificada-por-governo-de-mgpagar-multa-de-r-112-milhoes.html>. Acesso em: 21 nov. 2015.

- Notícias: Posicionamento sobre o comunicado da ONU. 25 nov. 2015b. Disponível em: http://www.samarco.com/2015/11/25/ comunicado-64/ Acesso em: 26 de nov. 2015.

diz que depositou R\$ 500 milhões de acordo com MP. G1 - Globo, Minas Gerais, 26 nov. 2015c. Disponível em: <http://g1.globo. $\mathrm{com} / \mathrm{minas}$-gerais/desastre-ambiental-emmariana/noticia/2015/11/samarco-diz-quedepositou-r-500-milhoes-de-acordo-com-omp.html>. Acesso em: 27 nov. 2015.

Demonstrações Financeiras Em 31 de dezembro de 2015. 2016. Disponível em: <http://www.samarco.com/wp-content/ uploads/2016/08/2015-DFs_portugues_ final_07062016.pdf>. Acesso em: 01 mai. 2016. 
SANTIAGO, Rosane. Patrimônio cultural de Mariana foi devastada. Diário do Rio Doce, Governador Valadares - MG, 21 nov. 2015. Disponível em: <http://www.drd.com.br/ news.asp?id $=50089800029022010000>$. Acesso em: 10 dez. 2015.

SMITH, Lawrence C.; SMITH, Murphy; ASHCROFT, Paul. Analysis of environmental and economic damages from British Petroleum's deepwater horizon oil spill. Albany Law Review, Vol. 74, no1, 2011, P. 563-585. Disponível em: <https://www.researchgate. net/publication/228264531_Analysis_of_ Environmental_and_Economic_Damages_ from_British_Petroleum's_Deepwater_ Horizon_Oil_Spill>. Acesso em: 17 mar. 2016.

TINKER, Tony; NIEMARK, Marilyn. The Role of Annual Reports in Gender and Class Contradictions at General Motors: 1917-1976. Accounting Organizations and Society, Vol. 12, no1, 1987, P. 71-88. Disponível em: <http:// www.sciencedirect.com/science/article/ pii/0361368287900171>. Acesso em: 11 jun. 2016.

VALE. Demonstrações Contábeis 31 de dezembro de 2015. Vale, 2016 Disponível em: <http://www.vale.com/PT/investors/ information-market/financial-statements/ FinancialstatementsDocs/itr_IFRS_ BRL_4T15p.pdf>. Acesso em: 5 mai. 2016.

YIN, Robert K. Estudo de caso: planejamento e métodos. Tradução de Daniel Grassi. 2a Edição. Porto Alegre: Bookman, 2001. 